\title{
0004 BEHAVIOUR BASED SAFETY IN INDIAN ORGANISATIONS
}

H L Kaila* Correspondence: Shiv Sagar Apartments, Bhabola Chulne Road, Vasai Road (West) - 401202, Mumbai, Maharashtra, India

10.1136/ip.2010.029215.4

This is a qualitative survey of 1500 executives and 400 workers based on an in-depth personal interviews and structured questionnaire using open-ended questions in a period of 10 years between 1997 and 2009 across Indian organizations (including petroleum, steel, cement, power, chemical etc) in 55 organisations in order to review the behaviour based safety in organizations. The narratives of executives and workers have provided a broad base in understanding behaviour based safety in Indian organisations. The implications are underlined for better organisational safety performance. This paper shall be useful in understanding and application of the concept and 


\section{IP Safety 2010 abstracts}

process of behaviour based safety for safety professionals and everyone who is concerned about correcting unsafe behaviours for reduction of accidents and promoting safe behaviours for developing injury-free culture in their organizations. The present paper is a pert of an on-going national action research project on the subject. 